\title{
DETERMINATION OF 5H-BENZO[2,3][1,4]OXAZEPINO[5,6-B]INDOLES IN RAT PLASMA BY REVERSED-PHASE HIGH-PERFORMANCE LIQUID CHROMATOGRAPHIC-ULTRAVIOLET METHOD: APPLICATION TO PHARMACOKINETIC STUDIES
}

\author{
ASHOK K SINGH, VINIT RAJ, AMIT RAI, AMIT K KESHARI, PRANESH KUMAR, SUDIPTA SAHA*
}

Department of Pharmaceutical Sciences, Babasaheb Bhimrao Ambedkar University, Vidya Vihar, Lucknow, Uttar Pradesh, India. Email: sudiptapharm@gmail.com

Received: 14 September 2017, Revised and Accepted: 13 November 2017

\section{ABSTRACT}

Objective: Recently, we reported newly synthesized 5H-benzo[2,3][1,4]oxazepino[5,6-b]indole) derivatives and proved their cytotoxicity against hepatocellular carcinoma specific Hep-G2 cell lines. We attempted herein to describe a reversed-phase high-performance liquid chromatographic method for the determination of three most active compounds 6a, 10a, and 15a in rat plasma to predict their pharmacokinetics parameters before in vivo study.

Methods: A rapid and sensitive reversed-phase high-performance liquid chromatographic was employed for the determination of $6 \mathrm{a}, 10 \mathrm{a}$, and $15 \mathrm{a}$ in rat plasma. Each compound was separated by a gradient elution of acetonitrile and water with $1 \mathrm{~mL} / \mathrm{min}$ flow rate. The detector was set at 270,285 , and $275 \mathrm{~nm}$ for $6 \mathrm{a}, 10 \mathrm{a}$, and $15 \mathrm{a}$ and the recorded elution times were $2.00,2.87$, and $1.88 \mathrm{~min}$, respectively.

Results: The calibration curve was linear with $\mathrm{R}^{2}$ of $0.938,0.875$, and 0.923 over the concentration range of $0.1-50 \mu \mathrm{g} / \mathrm{mL}$. The inter- and intraday variations of the assay were lower than $12.26 \%$; the average recovery of $6 \mathrm{a}, 10 \mathrm{a}$, and $15 \mathrm{a}$ was $97.31,92.56$, and $95.23 \%$ with relative standard deviation of $2.12 \%, 3.25 \%$, and $2.28 \%$, respectively. The $\mathrm{C}_{\max }$ and $\mathrm{T}_{\max }$ were $\sim 46.34,18.56$, and $25.65 \mu \mathrm{g} / \mathrm{mL}$ and $2.0,4.0$, and $4.0 \mathrm{~h}$ for $6 \mathrm{a}, 10 \mathrm{a}$, and $15 \mathrm{a}$, respectively, which indicate a robust method of detection in the present experiment.

Conclusion: The study suggests that all of the three compounds have a lower rate of absorption, higher volume of distribution, and lower clearance rate, indicating good therapeutic response for in vivo activity.

Keywords: $5 H$-benzo[2,3][1,4] oxazepino[5,6- $b]$ indoles, Reversed-phase high-performance liquid chromatographic, Pharmacokinetics, Rat plasma.

Graphical Abstract

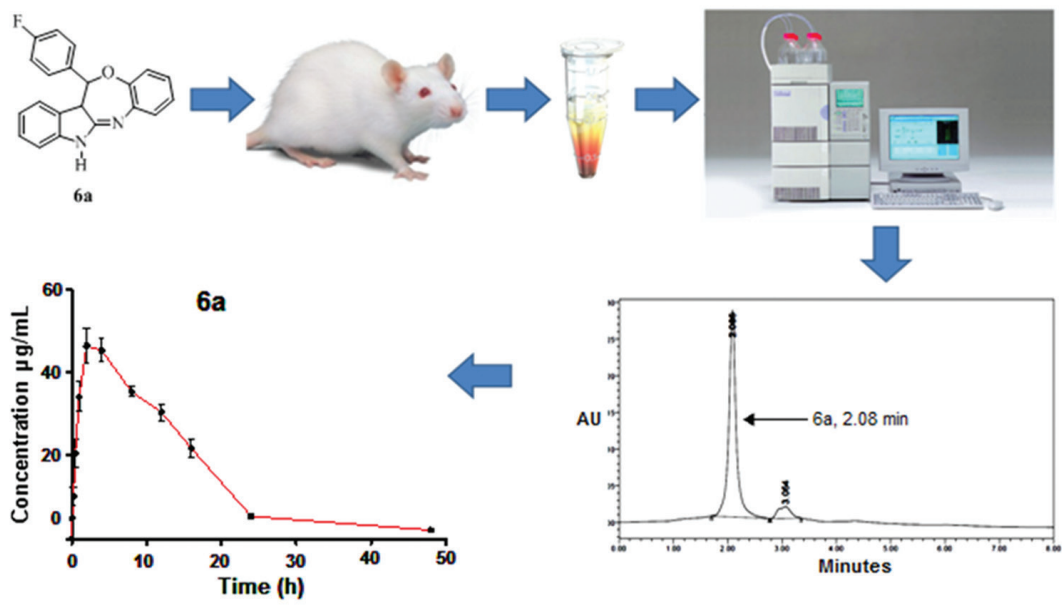

(c) 2017 The Authors. Published by Innovare Academic Sciences Pvt Ltd. This is an open access article under the CC BY license (http://creativecommons. org/licenses/by/4. 0/) DOI: http://dx.doi.org/10.22159/ajpcr.2017.v10i12.22565

\section{INTRODUCTION}

Nitrogen-containing heterocyclic ring generally offers a polarized character and establishes a most efficient interaction with the receptor molecules to produce anticancer effects [1]. Among them, indole is one of the widely reputed scaffolds to identify new drug candidate as anticancer agents [2-4]. In addition, various azepines and analogs have also been subject of much investigation for cancer drug discovery [5-7]. Later, a fusion of two or more heterocyclic rings in a single molecular frame has become an appealing method of drug design to enhance the synergistic effects [8]. Owing to the importance of N-heterocycles, individual role of indole and azepine in cancer prevention, and ring fusion concepts, development of indole-fused azepines may be of critical importance toward the potential success in cancer drug discovery. In addition, considering potency and in vitro cell line selectivity, several indole-fused azepines including paullones [9-14] open a new venture for the discovery of novel potential anticancer agents. Although several 
analogs of indole-fused azepines have been designed, synthesized, and screened for their cytotoxicity, there remain probably a space for the improvement in both efficacy and selectivity by the modification in ring structure.

In view of the aforementioned facts, recently [15], we designed and synthesized a new structural class indole-fused benzooxazepines (IFBO), particularly 5H-benzo[2,3][1,4] oxazepino[5,6-b]indoles derivatives, on the basis of molecular modeling on various related targets and evaluated them for in vitro antitumor potency against hepatocellular carcinoma (HCC)-specific Hep-G2 cell lines. Three compounds such as 6a, 10a, and 15a (Fig. 1) potentially inhibited the growth of tumor cells with $\mathrm{GI}_{50}<10 \mu \mathrm{g} / \mathrm{mL}$. Among these three derivatives, 4-fluoro derivative of $5 H$-benzo[2,3][1,4] oxazepino[5,6-b] indole $(6 \mathrm{a})$ demonstrated the most pronounced effect on $\%$ control growth of tumor cells.

A quantitative determination of newly synthesized compounds in rat plasma is a prerequisite criterion before in vivo experiment $[16,17]$. Thus, in continuation to our previous study, we described herein the pharmacokinetic studies of all the three compounds in rat plasma with an oral administration of $10 \mathrm{mg} / \mathrm{kg}$ dose. The study was performed using reverse-phase high-performance liquid chromatography (RPHPLC) attached with photodiode array detector (PDA). The intraand inter-day variations were analyzed to find the precision of the developed method. In addition, to evaluate the accuracy of the method, a recovery test was performed by spiking analytes into plasma with various standard solvents. The optimized method is simple and robust for detection of $5 \mathrm{H}$-benzo[2,3][1,4] oxazepino[5,6-b]indole derivatives in rat plasma. All the three active compounds $6 \mathrm{a}, 10 \mathrm{a}$, and $15 \mathrm{a}$ are shown in Fig. 1. The structures of these synthesized compounds were drawn in ChemDraw Ultra version 12 (Cambridge Soft).

\section{METHODS}

Chemicals

HPLC grade acetonitrile $(\mathrm{ACN})$, methanol $\left(\mathrm{CH}_{3} \mathrm{OH}\right)$, and water $\left(\mathrm{H}_{2} \mathrm{O}\right)$ were purchased from the Himedia Laboratories, Mumbai, India. All the compounds $6 \mathrm{a}, 10 \mathrm{a}$, and $15 \mathrm{a}$ were synthesized previously in our laboratory using the chemicals provided by Sigma-Aldrich and Himedia [15]. All other reagents used were of analytical grade.

\section{Animals and plasma samples collection}

Healthy Wister albino male rats (120-140 g) were purchased from the Experimental Animal Center, Lucknow, and the animal ethical committee already approved the study protocol (Approval No. SDCOP\&VS/AH/CPCSEA/01/0038/R2). The rats were caged standard laboratory conditions (temperature $25 \pm 5^{\circ} \mathrm{C}$ and light/dark cycle of $12 \mathrm{~h}$ ) and kept for 1 week for acclimatization. They maintained with free access to a commercial pellet diet and water ad libitium. The animal was fasted overnight before starting the experiment.
All the compounds (6a, 10a, and 15a) by dissolving into $0.25 \%$ carboxymethyl cellulose (CMC) were administered orally, and blood was collected at $0.00,0.083,0.25,0.5,1,2,4,8,12,16,24$, and $48 \mathrm{~h}$ time points from retro-orbital plexus $(n=3)$. Blood samples were collected into ethylenediaminetetraacetic acid containing $2 \mathrm{~mL}$ Eppendorf tube and centrifuged at 10,000 rpm for $10 \mathrm{~min}$ to separate the plasma and stored at $-80^{\circ} \mathrm{C}$ until analysis. HPLC analysis was carried out within 20 days of plasma samples collection.

\section{Chromatographic system and analytical conditions}

Chromatography separation was performed using the LC-10AD chromatograph (Shimadzu, Japan) with double pump, vacuum degasser, and 20- $\mu \mathrm{L}$ loop manual sample injector, interfaced with PDA detector (Shimadzu, Japan). All are controlled by the Shimadzu Lab Solutions CS software (version 5.3, Alltech, USA). The separation was performed using a Shimadzu RP- $\mathrm{C}_{18}$ column (5.0 $\mu$ particle size, $4.6 \mathrm{~mm}$ internal diameter, and $250 \mathrm{~mm}$ length). An isocratic elution system was employed with a mobile phase consisted of ACN and water in ratios of 9:1, 7:3, and 9.5:0.5 v/v for 6a, 10a, and 15a, respectively, which was freshly prepared and degassed by ultrasonication. The flow rate was set at $1 \mathrm{~mL} / \mathrm{min}$. During the analysis, the mobile phase was not allowed to recirculate during the analysis. The temperature was maintained at $40^{\circ} \mathrm{C}$ throughout the experiment, and the total run time was $6 \mathrm{~min}$. The column was washed after every run in an elution solvent ratio (50:50) with the injection of blank CAN.Chromatograms were monitored by UV detection in the range of $200-400 \mathrm{~nm}$ at a single wavelength, i.e., 270,285 , and $275 \mathrm{~nm}$ for $6 \mathrm{a}, 10 \mathrm{a}$, and $15 \mathrm{a}$, respectively.

\section{Preparation of standard solutions}

Stock solutions of $1 \mathrm{mg} / \mathrm{mL}$ for all the three compounds were prepared in ACN. Plasma stock solution of $50 \mu \mathrm{g} / \mathrm{mL}$ was prepared by spiking $10 \mathrm{~mL}$ of the stock solution into $190 \mathrm{~mL}$ of rat plasma. Later, standard solutions for calibration standards were prepared at a concentration of $0.1,0.5,1,2,5,10,25$, and $50 \mu \mathrm{g} / \mathrm{mL}(\mathrm{n}=3)$ by serial dilution. Quality control (QC) samples were prepared in triplicate at the concentrations of $0.4,2$, and $20 \mu \mathrm{g} / \mathrm{mL}$, representing low, medium, and high concentration QC samples, respectively [18]

Sample extraction, optimization, and preparation of calibrants and test samples

The extraction efficiency of all the compounds was evaluated from rat plasma using various solvents, i.e., $\mathrm{ACN}, \mathrm{ACN}$ : $\mathrm{H}_{2} \mathrm{O}$ (1:1), $\mathrm{CH}_{3} \mathrm{OH}$ and $\mathrm{CH}_{3} \mathrm{OH}: \mathrm{H}_{2} \mathrm{O}$ (1:1). The comparison of liquid-liquid extraction (LLE) was carried out using $100 \mu \mathrm{L}$ of $50 \mu \mathrm{g} / \mathrm{mL}$ concentration and $100 \mu \mathrm{L}$ of extracting solvent into a $2 \mathrm{~mL}$ Eppendorf tube. Then, the tubes were vortexed for $30 \mathrm{~min}$ and centrifuged at $10000 \mathrm{rpm}$ for $10 \mathrm{~min}$. Later, the supernatant was decanted out into another tube and dried in an oven at $40^{\circ} \mathrm{C}$. The tubes were reconstituted with $50 \mu \mathrm{L}$ of various mobile phases, vortexed for $10 \mathrm{~min}$, and $20 \mu \mathrm{L}$ was injected for HPLC-UV analysis. Area under curve (AUC) data were collected where ACN was found to be the best extracting solvent for all the compounds analyzed (Fig. 2). The figure was drawn on GraphPad Prism 5 trial version.<smiles>COc1ccc(C2Oc3ccccc3N=C3NNc4ccccc4C32)cc1O</smiles>

Fig. 1: Chemical structure of 6a (12-(4-fluorophenyl)-12,12a-dihydro-5H-benzo[2,3][1,4]oxazepino[5,6-b]indole), 10a (5-(12,12a-dihydro$5 \mathrm{H}$-benzo[2,3] [1,4]oxazepino[5,6-b]indol-12-yl)-2-methoxyphenol), and 15a (12-(2-bromophenyl)-12,12a-dihydro-5H-benzo[2,3][1,4] oxazepino[5,6-b]indole) 


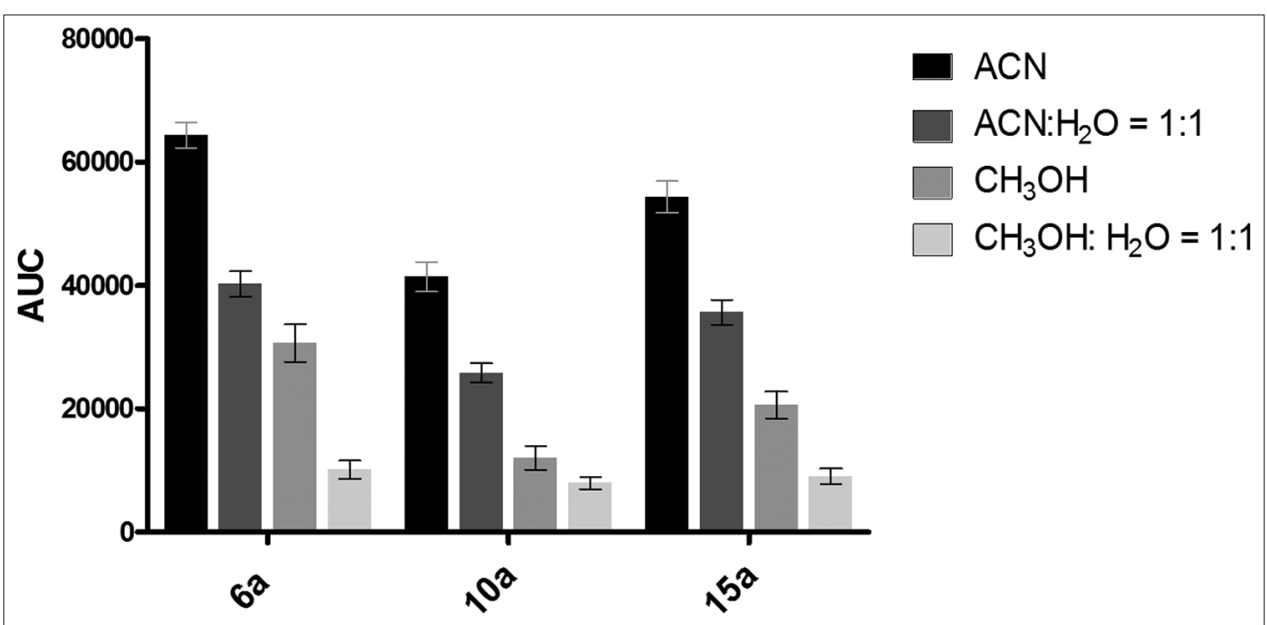

Fig. 2: Effects of solvents on area under curve of compounds 6a, 10a, and 15a in rat plasma. ACN: Actonitrile; $\mathrm{H}_{2} \mathrm{O}: \mathrm{Water}_{3} \mathrm{CH}_{3} \mathrm{OH}$ : Methanol; all the three compounds 6a, 10a, and 15a are IFBO derivatives. Data are given in mean \pm SD $(n=3)$

For the preparation of calibration curve, the above-mentioned calibrants $(100 \mu \mathrm{L})$ were taken into Eppendorf tube, and $100 \mu \mathrm{L}$ blank ACN was added to it. The remaining procedure was similar to a previously described method. For test compounds, $100 \mu \mathrm{L}$ of various time point samples were taken into Eppendorf tube, and $100 \mu \mathrm{L}$ of blank ACN was added to it. Other procedures are same as previous one.

\section{Stability studies}

Long-term stability of $6 \mathrm{a}, 10 \mathrm{a}$, and $15 \mathrm{a}$ was performed by preparing QC samples at three concentration ranges in three replicates such as low $(0.1 \mu \mathrm{g} / \mathrm{mL})$, medium $(5 \mu \mathrm{g} / \mathrm{mL})$, and high $(50 \mu \mathrm{g} / \mathrm{mL})$ for four dissimilar days and stored at $4{ }^{\circ} \mathrm{C}$. The analysis of all these samples was performed after $0,7,15$, and 30 days of storage, and the data of samples were calculated by the particular calibration standard curve. The results revealed as $\%$ deviation from 0 days concentration. Moreover, the short-term stability of all the compounds was also performed at room temperature over $8 \mathrm{~h}$ by analyzing replicates $(n=3)$ at three $Q C$ levels.

\section{Method validation}

The developed method was validated in terms of selectivity, linearity, accuracy (\% recovery), and precision (intra- and inter-day variability with \% relative standard deviation [RSD]), lower limits of quantification (LLOQ) according to the accepted guidelines $[19,20]$. Linearity was assessed over a concentration range of $0.1-50 \mu \mathrm{g} / \mathrm{mL}$ at seven different concentration levels. The intra- and inter-day variability was confirmed by calculating $\%$ bias from the theoretical concentration using equation: $\%$ bias $=$ (observed concentration - nominal concentration $) /$ nominal concentration $\times 100$ ) [21]. The intra- and inter-day precisions were calculated by subjecting the data to the one-way analysis of variance respective to their \% RSD

\section{Pharmacokinetic study}

The developed method was utilized in evaluations of pharmacokinetic parameters of all the compounds in rat plasma. All the pharmacokinetic parameters such as maximum plasma concentration $\left(\mathrm{C}_{\max }\right)$, time of maximum concentration $\left(\mathrm{T}_{\max }\right), \mathrm{AUC}$ at infinite time $\left(\mathrm{AUC}_{0-\infty}\right)$, mean residential time (MRT), and clearance rate (CL) were calculated using WinNonlins (5.1 software, trial version).

\section{RESULTS AND DISCUSSION}

In our recent investigation, three compounds $6 \mathrm{a}, 10 \mathrm{a}$, and $15 \mathrm{a}$ derived from a novel structural class $5 \mathrm{H}$-benzo[2,3][1,4] oxazepino[5,6-b] indoles exhibited a remarkable cytotoxicity profile against HCC-specific Hep-G2 cell line. In continuation to this finding and before performing in vivo animal study, we wished to assure whether these drugs have a satisfactory absorption, distribution, and clearance rate that would serve a considerable therapeutic response. To accomplish the goal, we investigated the oral pharmacokinetics properties of all the three active compounds in rat plasma with an oral administration of $10 \mathrm{mg} / \mathrm{kg}$ dose. The study was conducted using RP-HPLC method for the determination of $5 \mathrm{H}$-benzo[2,3][1,4] oxazepino[5,6-b]indoles in rat plasma, and pharmacokinetic parameters were calculated by software using the obtained data. All plasma samples were analyzed successfully using HPLC to achieve better selectivity, sensitivity, and reproducibility of $6 a$, $10 \mathrm{a}$, and $15 \mathrm{a}$ in rat plasma.

\section{Optimization of plasma sample pre-treatment conditions}

LLE is a well-established technique for the extraction of concentrated, high-purity compounds from a broad range of biological samples. An appropriate LLE solvent is often used to eliminate the sample medium and take out the analyte since matrix effect occurs due to the presence of other ions in the biological sample [22,23]. A number of common organic solvents such as dichloromethane, chloroform, ACN, and methanol were used to extract $6 \mathrm{a}, 10 \mathrm{a}$, and $15 \mathrm{a}$ from spiked blood plasma. Among them, ACN was found the most efficient solvent for the recovery of all the three compounds under reduced milieu effects. It has also been observed that better peak shapes and shorter retention times (RT) were obtained with ACN as compared to other solvents as an organic phase. The signal intensities for these compounds were steadily increased on increasing the percentage of ACN from $10 \%$ to $90 \%$ and slowly decreased from 90\%. LLE followed by HPLC analysis revealed that all the compounds $6 \mathrm{a}, 10 \mathrm{a}$, and $15 \mathrm{a}$ were of non-polar nature. Meanwhile, we played with an eluting solvent in different ratios of ACN: $\mathrm{H}_{2} \mathrm{O}$ to separate out $6 \mathrm{a}$ in HPLC column. It was observed that the ratio 9:1 v/v allowed the highest AUC with a RT of 2.08 min (Fig. 3a). Thus, we decided to elute 6a using ACN and $\mathrm{H}_{2} \mathrm{O}$ in a ratio of 9:1. Similarly, as per the better AUC obtained, separation of 10a and 15a was performed using an eluting solvent in the ratios of 7:3 and 9.5:0.5 v/v with RT of 2.87 and $1.88 \mathrm{~min}$, respectively (Fig. $3 \mathrm{~b}$ and c).

Fig. 3 shows a typical HPLC chromatogram obtained after the injection of a standard solution of $6 a, 10 a$, and 15 a where no interfering peak was observed that suggests the specificity of the method and its suitability for the routine $\mathrm{QC}$ analyses. Later, this optimized method was adopted to run the calibrants, QC, and test samples. Finally, data were calculated through WinNonlin 5.1 trial version.

\section{Method validation}

The developed method was used to validate in term of specificity, linearity, LLOQ accuracy (\% recovery), and precision (intra- and inter-day variability with \% RSD). The proposed method was fully validated according to international guidelines [19,20,24]. To verify the specificity of method, blank natural plasma samples aspirated from rats and the rat plasma spiked with $6 \mathrm{a}, 10 \mathrm{a}$, and $15 \mathrm{a}$ were analyzed, 
and possible interferences with the analytes were observed by visual comparison of chromatograms with those obtained from the respective samples. To evaluate the linearity of the HPLC method, calibration curves were constructed and linearity was established by the leastsquares linear regression. Best linearity was obtained between the analyte peak area and the corresponding concentrations over a wide range of $0.1-50 \mu \mathrm{g} / \mathrm{mL}$ with $\mathrm{R}^{2}$ of $0.938,0.875$, and 0.923 for $6 \mathrm{a}, 10 \mathrm{a}$, and $15 \mathrm{a}$, respectively. The LLOQ was found to be $0.01 \mu \mathrm{g} / \mathrm{mL}$, which makes the optimized method useful for a wide range of derivatives and exhibits a high sensitivity for drug monitoring and pharmacokinetic studies. The precision was determined by calculating RSD values of six consecutive injections of the working standard solutions of $6 \mathrm{a}, 10 \mathrm{a}$, and $15 \mathrm{a}$ in three replicates. The \% RSD was observed within the limit of $\pm 20 \%$ for all the three compounds which are acceptable for the routine measurement (Table 1).

The accuracy of method was determined by analyzing the percentage recovery of $6 a, 10 a$, and $15 a$ in plasma samples. We assessed the accuracy of the method by repeated analytical recovery of three known concentrations $(0.1,0.5$, and $1 \mu \mathrm{g} / \mathrm{mL})$ for $6 \mathrm{a}, 10 \mathrm{a}$, and $15 \mathrm{a}$, respectively, in three replicates. The average recovery of $6 \mathrm{a}, 10 \mathrm{a}$, and 15 a was $97.31 \%, 92.56 \%$, and $95.23 \%$ with RSD of $2.12 \%, 3.25 \%$, and $2.28 \%$, respectively, which showed the accuracy of the method. Stability of compounds in rat plasma is another important parameter often considered for every pharmacokinetic study. All the three compounds were found to be stable over 30 days in normal plasma when stored

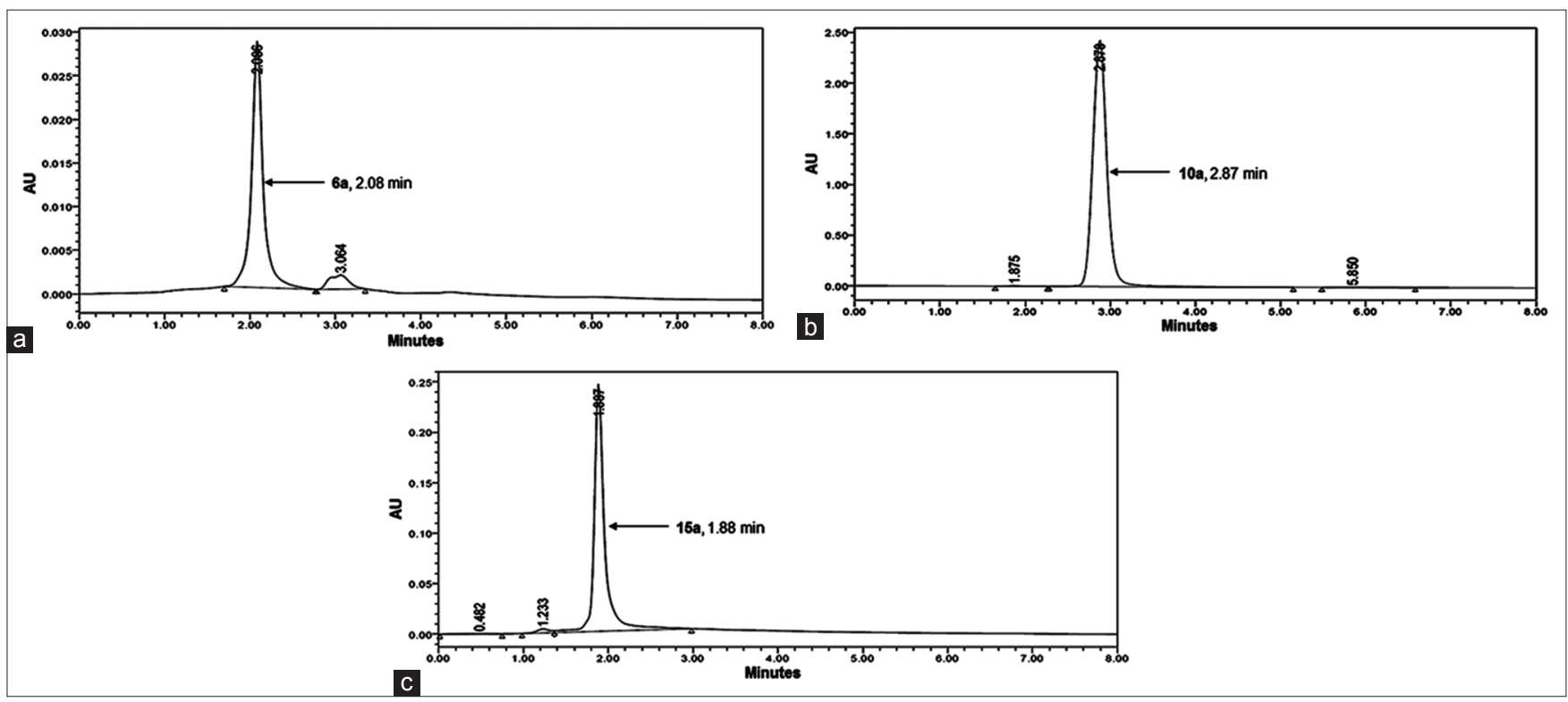

Fig. 3: High-performance liquid chromatography of (a) 6a, (b) 10a, and (c) 15a. The observed retention time was 2.00, 2.87, and 1.88 min for compounds $6 \mathrm{a}, 10 \mathrm{a}$, and $15 \mathrm{a}$, respectively

Table 1: The intra- and inter-day precision of $6 a, 10 a$, and $15 a$ in rat plasma

\begin{tabular}{|c|c|c|c|c|c|}
\hline \multirow[t]{2}{*}{ Compounds } & \multirow[t]{2}{*}{ Spiked concentration $(\mu \mathrm{g} / \mathrm{mL})$} & \multicolumn{2}{|c|}{ Intra-day precision $(n=3)$} & \multicolumn{2}{|c|}{ Inter-day precision $(n=3)$} \\
\hline & & $\operatorname{Mean} \pm \operatorname{SD}(\mu \mathrm{g} / \mathrm{mL})$ & RSD (\%) & $\operatorname{Mean} \pm \operatorname{SD}(\mu \mathrm{g} / \mathrm{mL})$ & RSD (\%) \\
\hline \multirow[t]{8}{*}{$6 a$} & 0.1 & $0.08 \pm 0.002$ & 2.91 & $0.09 \pm 0.002$ & 2.34 \\
\hline & 0.5 & $0.51 \pm 0.05$ & 12.26 & $0.58 \pm 0.02$ & 7.85 \\
\hline & 1 & $0.89 \pm 0.07$ & 6.27 & $0.82 \pm 0.09$ & 9.29 \\
\hline & 2 & $1.95 \pm 0.25$ & 9.71 & $1.89 \pm 0.26$ & 10.90 \\
\hline & 5 & $5.04 \pm 0.48$ & 8.85 & $5.55 \pm 0.31$ & 5.85 \\
\hline & 10 & $10.49 \pm 0.51$ & 6.06 & $10.77 \pm 0.38$ & 6.59 \\
\hline & 25 & $24.46 \pm 0.88$ & 4.78 & $26.79 \pm 0.97$ & 5.20 \\
\hline & 50 & $48.67 \pm 1.21$ & 3.76 & $50.66 \pm 1.36$ & 4.14 \\
\hline \multirow[t]{8}{*}{$10 \mathrm{a}$} & 0.1 & $0.1 \pm 0.001$ & 1.38 & $0.2 \pm 0.002$ & 1.47 \\
\hline & 0.5 & $0.44 \pm 0.05$ & 10.36 & $0.52 \pm 0.04$ & 5.88 \\
\hline & 1 & $1.14 \pm 0.06$ & 4.85 & $1.35 \pm 0.06$ & 4.07 \\
\hline & 2 & $2.24 \pm 0.12$ & 7.01 & $2.44 \pm 0.18$ & 5.89 \\
\hline & 5 & $4.79 \pm 0.22$ & 6.85 & $4.64 \pm 0.19$ & 6.74 \\
\hline & 10 & $10.24 \pm 0.35$ & 4.09 & $10.67 \pm 0.28$ & 4.98 \\
\hline & 25 & $25.67 \pm 0.76$ & 3.28 & $25.98 \pm 0.68$ & 3.82 \\
\hline & 50 & $49.76 \pm 1.06$ & 2.16 & $50.43 \pm 1.34$ & 2.74 \\
\hline \multirow[t]{8}{*}{$15 \mathrm{a}$} & 0.1 & $0.4 \pm 0.001$ & 2.56 & $0.3 \pm 0.003$ & 2.58 \\
\hline & 0.5 & $0.48 \pm 0.06$ & 11.33 & $0.58 \pm 0.05$ & 6.80 \\
\hline & 1 & $1.05 \pm 0.07$ & 4.85 & $1.19 \pm 0.08$ & 5.85 \\
\hline & 2 & $1.84 \pm 0.22$ & 8.68 & $1.99 \pm 0.19$ & 7.16 \\
\hline & 5 & $4.99 \pm 0.32$ & 6.85 & $5.14 \pm 0.28$ & 6.14 \\
\hline & 10 & $10.34 \pm 0.41$ & 4.89 & $10.17 \pm 0.38$ & 4.98 \\
\hline & 25 & $24.97 \pm 0.94$ & 2.98 & $25.48 \pm 0.84$ & 3.82 \\
\hline & 50 & $50.66 \pm 1.56$ & 1.76 & $50.81 \pm 1.73$ & 1.87 \\
\hline
\end{tabular}

Mean: Average of number of experiment, SD: Standard deviation, RSD: Relative standard deviation. Data are given in mean \pm SD $(\mathrm{n}=3)$ 
at $4{ }^{\circ} \mathrm{C}$. The short-term stability was carried out at room temperature over $8.0 \mathrm{~h}$ and long-term also performed after 30 days preservation using three replicates at three concentration levels. The percent deviation was calculated and found within acceptable range (Table 2). The calculated stability of spiked plasma indicated that $6 \mathrm{a}, 10 \mathrm{a}$. and $15 \mathrm{a}$ had no considerable degradation under the above-mentioned environmental condition.

\section{Pharmacokinetic study}

The newly developed and validated method was utilized in the pharmacokinetic study of 5H-benzo[2,3][1,4] oxazepino[5,6-b]indole derivatives after the single oral administration of $10 \mathrm{mg} / \mathrm{kg}$ dose. The mean plasma concentration-time profile of compounds $6 \mathrm{a}, 10 \mathrm{a}$, and $15 \mathrm{a}$ in male Wistar rats is shown in Fig. 4. The figure was drawn on GraphPad Prism 5 trial version.

The calculated non-compartment model parameters of pharmacokinetic study are summarized in Table 3 where the maximum plasma concentration $\left(\mathrm{C}_{\max }\right)$, time of maximum exposure $\left(\mathrm{T}_{\max }\right)$, and AUC at infinite time ( $A U C_{0}$ ) were found to be $46.34 \pm 0.92 \mu \mathrm{g} / \mathrm{mL}, 2.0 \mathrm{~h}$, $747.18 \pm 18.31 \mu \mathrm{g} . \mathrm{h} / \mathrm{mL}$ for $6 \mathrm{a}, 18.56 \pm 0.75 \mu \mathrm{g} / \mathrm{mL}, 4.0 \mathrm{~h}, 256.78 \pm 10.21$ $\mu \mathrm{g} . \mathrm{h} / \mathrm{mL}$ for $10 \mathrm{a}$, and $25.65 \pm 0.83 \mu \mathrm{g} / \mathrm{mL}, 4.0 \mathrm{~h}, 376.22 \pm 12.21 \mu \mathrm{g} . \mathrm{h} / \mathrm{mL}$ for $15 a$, respectively.

The data represented in Fig. 4 clearly explained that all the three compounds have slow absorption rate which is useful for liver cancer treatment as they remain in gastrointestinal tract in higher amount for long time. Although all the three compounds exhibit good pharmacokinetic property, compound 6a showed promising pharmacokinetic behavior among all the three compounds as it shows maximum concentration within optimum time duration. The MRT was found as $11.64 \pm 0.28,12.70 \pm 1.31$, and $11.58 \pm 1.20 \mathrm{~h}$ for $6 \mathrm{a}, 10 \mathrm{a}$, and $15 \mathrm{a}$, respectively, indicating that all the three compounds have higher volume of distribution. Compound 6a has higher clearance rate (CL) than those of compounds $10 \mathrm{a}$ and $15 \mathrm{a}$ again signified its better effectiveness.

\section{CONCLUSION}

Our recently reported compounds 5H-benzo[2,3][1,4] oxazepino[5,6-b] indoles hold a promise to be a potential drug candidate for liver cancer treatment through in vitro cell line study. Before performing the in vivo

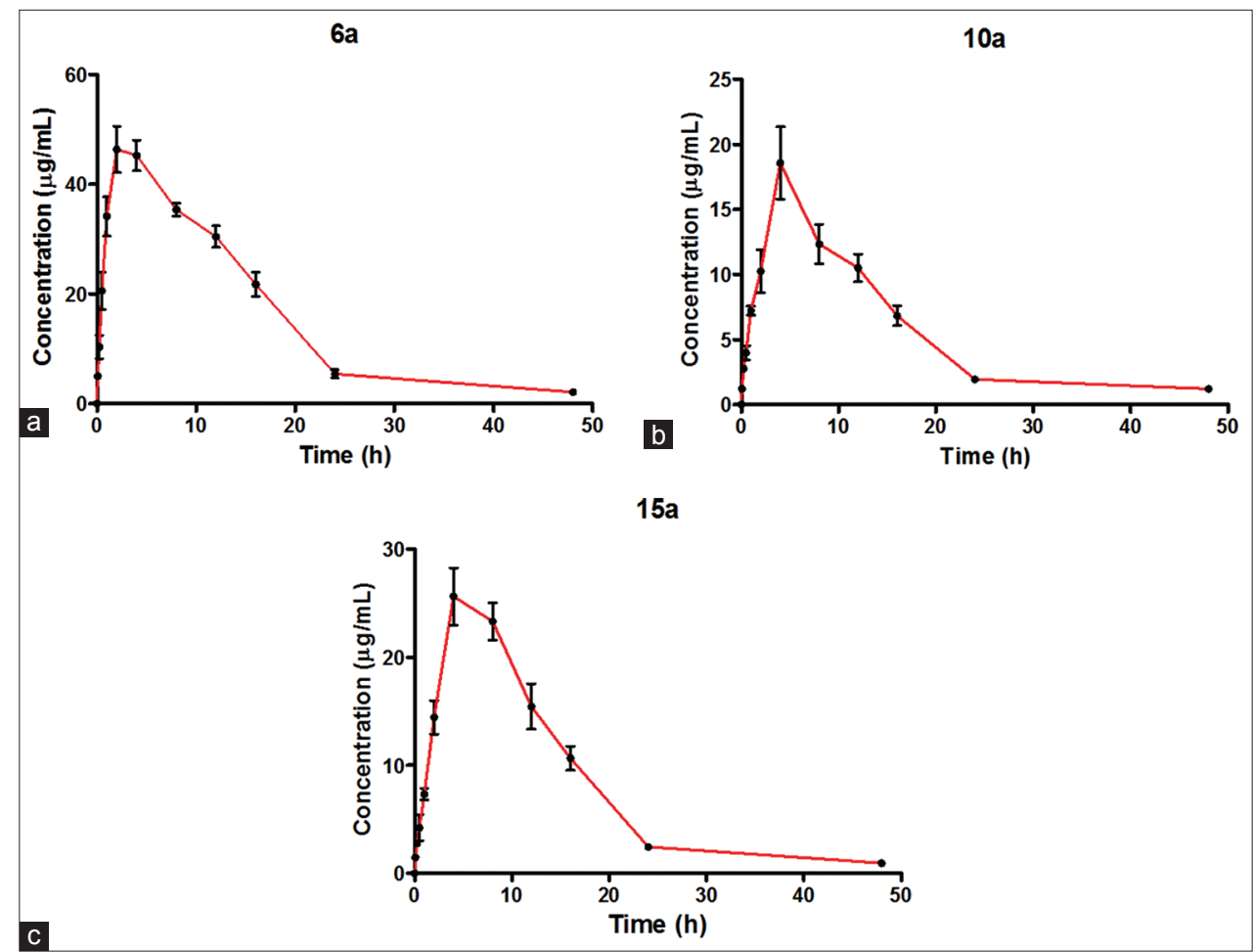

Fig. 4: (a-c) Plasma drug concentrations after single oral administration of compounds 6a, 10a, and 15a at $25 \mathrm{mg} / \mathrm{kg}$. Data are given in mean $\pm S D(n=3)$

Table 2: The short- and long-term stability of $6 a, 10 a$. and $15 a$ in rat plasma

\begin{tabular}{|c|c|c|c|c|c|}
\hline \multirow[t]{2}{*}{ Compounds } & \multirow[t]{2}{*}{ Spiked concentration $(\mu \mathrm{g} / \mathrm{mL})$} & \multicolumn{2}{|l|}{ Short-term stability } & \multicolumn{2}{|l|}{ Long-term stability } \\
\hline & & $\operatorname{Mean} \pm \operatorname{SD}(\mu \mathrm{g} / \mathrm{mL})$ & RSD (\%) & $\operatorname{Mean} \pm \operatorname{SD}(\mu \mathrm{g} / \mathrm{mL})$ & RSD (\%) \\
\hline \multirow[t]{3}{*}{$6 a$} & 0.1 & $0.08 \pm 0.002$ & 2.05 & $0.07 \pm 0.001$ & 2.25 \\
\hline & 5 & $5.46 \pm 0.27$ & 3.08 & $5.18 \pm 0.44$ & 3.36 \\
\hline & 50 & $50.65 \pm 2.38$ & 2.80 & $50.78 \pm 2.32$ & 2.15 \\
\hline \multirow[t]{3}{*}{$10 \mathrm{a}$} & 0.1 & $0.15 \pm 0.002$ & 1.63 & $0.10 \pm 0.001$ & 1.21 \\
\hline & 5 & $5.35 \pm 0.81$ & 4.17 & $5.48 \pm 0.24$ & 5.12 \\
\hline & 50 & $50.43 \pm 2.84$ & 2.80 & $50.70 \pm 2.30$ & 2.15 \\
\hline \multirow{3}{*}{$15 \mathrm{a}$} & 0.1 & $0.11 \pm 0.002$ & 1.53 & $0.17 \pm 0.001$ & 0.98 \\
\hline & 5 & $5.05 \pm 0.74$ & 4.98 & $5.48 \pm 0.45$ & 4.47 \\
\hline & 50 & $50.23 \pm 2.13$ & 2.27 & $50.85 \pm 2.36$ & 2.32 \\
\hline
\end{tabular}

Mean: Average of number of experiment, SD: Standard deviation, RSD: Relative standard deviation. Data are given in mean \pm SD ( $\mathrm{n}=3$ ) 
Table 3: Pharmacokinetic parameters of $6 a, 10 a$, and 15a after oral dose administration

\begin{tabular}{llll}
\hline Parameters & $\mathbf{6 a}$ & $\mathbf{1 0 a}$ & $\mathbf{1 5 a}$ \\
\hline $\mathrm{C}_{\max }(\mu \mathrm{g} / \mathrm{mL})$ & $46.34 \pm 0.92$ & $18.56 \pm 0.75$ & $25.65 \pm 0.83$ \\
$\mathrm{~T}_{\max }(\mathrm{h})$ & 2.00 & 4.00 & 4.00 \\
$\mathrm{AUC}_{0-\infty}(\mu \mathrm{g} . \mathrm{h} / \mathrm{mL})$ & $747.18 \pm 18.31$ & $256.78 \pm 10.21$ & $376.22 \pm 12.21$ \\
$\mathrm{AUMC}\left(\mu \mathrm{g} \cdot \mathrm{h}^{2} / \mathrm{mL}\right)$ & 8697.57 & 3261.16 & 4358.09 \\
$\mathrm{MRT}(\mathrm{h})$ & $11.64 \pm 0.28$ & $12.70 \pm 1.31$ & $11.58 \pm 1.20$ \\
$\mathrm{CL}\left(\mathrm{h}^{-1}\right)$ & 0.280 & 0.008 & 0.065 \\
\hline
\end{tabular}

$\mathrm{C}_{\max }:$ Maximum drug concentration in plasma, $\mathrm{T}_{\max }$ : Time at which the $\mathrm{C}_{\max }$ observed, AUC: Area under curve, AUMC: Area under the first movement curve, MRT: Mean residual time, $C L$ : Clearance rate. Data are given in mean $\pm S D(n=3)$

animal study, it was necessary to explore the pharmacokinetic profiles to assure the real fate of these newly synthesized compounds in rat plasma. We, therefore, developed and validated a RP-HPLC method using a LLE technique for the quantification of our recently synthesized compounds $6 \mathrm{a}, 10 \mathrm{a}$, and $15 \mathrm{a}$ in rat plasma. Results obtained from our experiment clearly exhibited that all the three compounds have a lower rate of absorption, higher volume of distribution, and lower clearance rate that particularly indicate a good pharmacological response. The newly optimized methods for $6 \mathrm{a}, 10 \mathrm{a}$, and $15 \mathrm{a}$ may be more robust with respect to accuracy and precision. Thus, all the three newly synthesized compounds are suitable for further in vivo study using chemically induced HCC rat model.

\section{ACKNOWLEDGMENT}

The authors wish to express their thanks to the Department of Pharmaceutical Sciences, Babasaheb Bhimrao Ambedkar University, Lucknow, India, for providing the HPLC and research facilities.

\section{REFERENCES}

1. Ozkay Y, Issikdağ I, Incesu Z, Akalin G. Synthesis of 2-substitutedN-[4-(1-methyl-4,5-diphenyl-1H-imidazole-2-yl)phenyl]acetamide derivatives and evaluation of their anticancer activity. Eur J Med Chem 2010;45:3320-8

2. Yan J, Hu J, An B, Huang L, Li X. Design, synthesis, and biological evaluation of cyclic-indole derivatives as anti-tumor agents via the inhibition of tubulin polymerization. Eur J Med Chem 2017;125:663-75.

3. Fortes MP, da Silva PB, da Silva TG, Kaufman TS, Militão GC, Silveira CC, et al. Synthesis and preliminary evaluation of 3-thiocyanato-1H-indoles as potential anticancer agents. Eur J Med Chem 2016;118:21-6.

4. Zhou J, Feng JH, Fang L. A novel monoterpenoid indole alkaloid with anticancer activity from Melodinus khasianus. Bioorg Med Chem Lett 2017;27:893-6.

5. Rajanarendar E, Reddy MN, Krishna SR, Reddy KG, Reddy YN, Rajam MV. Design, synthesis, in vitro antimicrobial and anticancer activity of novel methylenebis-isoxazolo $[4,5-b]$ azepines derivatives. Eur J Med Chem 2012:50:344-9.

6. Rajanarendar E, Nagi Reddy M, Rama Murthy K, Surendar P, Reddy RN, Reddy $\mathrm{YN}$, et al. Synthesis and in vitro and in vivo anticancer activity of novel phenylmethylene bis-isoxazolo [4, 5-b] azepines. Bioorg Med
Chem Lett 2012;22:149-53.

7. Gu X, Tang X, Zhao Q, Peng H, Peng S, Zhang Y, et al. Discovery of alkoxyl biphenyl derivatives bearing dibenzo [c, e] azepine scaffold as potential dual inhibitors of P-glycoprotein and breast cancer resistance protein. Bioorg Med Chem Lett 2014;24:3419-21.

8. Akhtar J, Khan AA, Ali Z, Haider R, Shahar Yar M. Structure-activity relationship (SAR) study and design strategies of nitrogen-containing heterocyclic moieties for their anticancer activities. Eur J Med Chem 2017;125:143-89.

9. Kumar KS, Ramulu MS, Rajesham B, Kumar NP, Voora V, Kancha RK. $\mathrm{FeCl}_{3}$ catalysed 7-membered ring formation in a single pot: A new route to indole-fused oxepines/azepines and their cytotoxic activity. Org Biomol Chem 2017;15:4468-76.

10. Kunick C, Schultz C, Lemcke T, Zaharevitz DW, Gussio R, Jalluri RK, et al 2-substituted paullones: CDK1/cyclin B-inhibiting property and in vitro antiproliferative activity. Bioorg Med Chem Lett 2000;10:567-9.

11. Power DP, Lozach O, Meijer L, Grayson DH, Connon SJ. Concise synthesis and $\mathrm{CDK} / \mathrm{GSK}$ inhibitory activity of the missing 9-azapaullones. Bioorg Med Chem Lett 2010;20:4940-4.

12. Kunick C, Lauenroth K, Leost M, Meijer L, Lemcke T. 1-azakenpaullone is a selective inhibitor of glycogen synthase kinase-3 beta. Bioorg Med Chem Lett 2004;14:413-6.

13. Becker A, Kohfeld S, Lader A, Preu L, Pies T, Wieking K, et al. Development of 5-benzylpaullones and paullone-9-carboxylic acid alkyl esters as selective inhibitors of mitochondrial malate dehydrogenase (mMDH). Eur J Med Chem 2010;45:335-42.

14. Keller L, Beaumont S, Liu JM, Thoret S, Bignon JS, WdzieczakBakala J, et al. New C5-alkylated indolobenzazepinones acting as inhibitors of tubulin polymerization: Cytotoxic and antitumor activities. J Med Chem 2008;51:3414-21

15. Singh AK, Raj V, Rai A, Keshari AK, Saha S. Indole-fused benzooxazepines: A new structural class of anticancer agents. Future Sci OA 2017;3:FSO168.

16. Poulin P, Theil FP. Prediction of pharmacokinetics prior to in vivo studies 1. Mechanism-based prediction of volume of distribution. J Pharm Sci 2002;91:129-56.

17. Poulin P, Theil FP. Prediction of pharmacokinetics prior to in vivo studies. II. Generic physiologically based pharmacokinetic models of drug disposition. J Pharm Sci 2002;91:1358-70.

18. D'cruz D, Babu A, Joshy E, Aneesh TP. Bio analytical method development and validation of ticagrelor by RP-HPLC. Int J App Pharm 2017:9:951-54

19. The United State Pharmacopeia. 34/The National Formulary 29. Rockville, Md: US Pharmacopeial Convention; 2011. p. 778-82.

20. Validation of Analytical Procedures: Text and Methodology. ICHGuideline Q2 (R1). 1996. Available from: http://www.ICH.org.

21. Shah S, Dhanani T, Kumar S. Validated HPLC method for identification and quantification of p-hydroxy benzoic acid and agnuside in Vitex negundo and Vitex trifolia. J Pharm Anal 2013;3:500-8

22. Tijare LK, Rangari NT, Mahajan UN. A review on bio analytical method development and validation. Asian J Pharm Clin Res 2016;9:6-10.

23. Ruzilawati $A B$, Miran $H$. Validated high performance liquid chromatography method for analysis of methamphetamine in human urine using liquid-liquid extraction. Asian J Pharm Clin Res 2015;8:199-201.

24. Nafissi-Varcheh N, Shafaati A, Zarghi A, Aboofazeli R. Separation of somatropin and its degradation products by high-performance liquid chromatography using a reversed-phase polymeric column. Iran J Pharm Res 2004:4:209-213. 